\title{
Covid-19 and "Immune Boosting" on the Internet: A Content Analysis of Google Search Results
}

\author{
Christen Rachul ${ }^{1 *}$, Alessandro R. Marcon², Benjamin Collins ${ }^{1,3}$, Timothy Caulfield ${ }^{2,4,5}$ \\ ${ }^{1}$ Rady Faculty of Health Sciences, University of Manitoba; ${ }^{2}$ Health Law Institute, \\ University of Alberta; ${ }^{3}$ Department of Anthropology, University of Manitoba; \\ ${ }^{4}$ Faculty of Law, University of Alberta; ${ }^{5}$ School of Public Health, University of Alberta \\ *Corresponding Author: christen.rachul@umanitoba.ca
}

\begin{abstract}
Background: The spread of misinformation has accompanied the coronavirus pandemic, including topics such as immune boosting to prevent COVID-19. This study explores how immune boosting is portrayed on the Internet during the COVID-19 pandemic.
\end{abstract}

Methods: We conducted a content analysis of 227 webpages compiled from Google searches in Canada and the US using the phrase "immune boosting" AND "coronavirus". We coded webpages for typology, portrayal of immune boosting and supplements. We also recorded mentions of microbiome, whether the webpage was selling or advertising an immune boosting product or service, and any suggested strategies for boosting immunity.

Results: No significant differences were found between webpages that appeared in the searches in Canada and the US. The most common types of webpages were from news sites (40.5\%) and commercial sites (24.7\%). The concept of immune boosting was portrayed as beneficial for avoiding COVID-19 in 85.5\% of webpages and $40 \%$ of the webpages portrayed supplements as beneficial, but commercial sites were more likely to have these portrayals. The top immune boosting strategies were vitamin C (34.8\%), diet (34.8\%), sleep (34.4\%), exercise (30.8\%), and zinc (26.9\%). Less than $10 \%$ of the webpages provide any critique of the concept of immune boosting.

Interpretation: Pairing evidence-based advice for maintaining one's health (e.g., healthy diet, exercise, sleep) with the phrase immune boosting and strategies lacking in evidence may inadvertently help to legitimize the concept, making it a powerful marketing tool. Results demonstrate how the spread of misinformation is complex and often more subtle than blatant fraudulent claims.

This working paper has not yet been peer-reviewed. May $19^{\text {th }}, 2020$ 


\section{Introduction}

The coronavirus pandemic has been accompanied by the spread of misinformation on topics that include the marketing of and speculation on possible cures, treatments and preventative strategies. Some scholars have noted that this "infodemic" - as the World Health Organization called it - has already resulted in considerable harm. ${ }^{1-4}$ Specifically, this infodemic is associated with deaths, delayed treatment, wasted resources, and substantive concerns that it adds to an already confused and chaotic information environment. ${ }^{5-7}$

Boosting the immune system is a common theme associated with many of the products and practices presented as strategies to avoid or help fight COVID-19. Indeed, a Google Trends analysis reveals that searches for phrases like "immune boost" and "immune boosting" spiked in early February, 2020, as concern about the impact of the virus started to intensify. However, the concept of immune boosting is misleading and scientifically inaccurate.8,9 The immune system is fantastically complex and researchers are still exploring how various nutrients impact its performance, with overly active immune systems potentially leading to autoimmune diseases and anaphylaxis. Some early research studies have also suggested that an exaggerated immune response is implicated in respiratory failure in patients with COVID-19.10 There is no evidence that any product or practice - aside from a vaccine - will provide extra or enhanced "immune boosting" protection against COVID-19.

Despite this reality, celebrities, wellness gurus and supplement companies have been making claims about the need and ways to boost our immune system. ${ }^{11}$ These popularisations are entangled with the general public's belief that supplements improve a body's immune system, ${ }^{12,13}$ resulting in immune boosting becoming commonly associated with pop culture representations of COVID-19. Additionally, there is some evidence that the kinds of COVID-19 information that people are exposed to affects their health-related behaviours and attitudes. ${ }^{14,15}$ As such, the public responses to the pandemic in Canada and the US warrant further exploration of how misinformation may impact on perceptions of how to prevent and protect against COVID-19.16,17 This study therefore focuses on how immune boosting and supplements are being portrayed with respect to COVID-19 in Canada and the US.

\section{Methods}

\section{Data Collection}

Following Macedo et al., ${ }^{18}$ we conducted searches on Google Chrome ${ }^{\circledR}$, the most widely used search engine, ${ }^{19}$ using the phrase "boost immunity" AND "coronavirus" on April 1, 2020 in Winnipeg, Canada to compile a dataset of URLs for analysis. To limit personalization of the search results, we did not link the browser to an existing Google account, and we deleted cookies and erased the browser history. We conducted advanced searches, which allowed us to select regional settings. We first conducted a search with the region set to Canada, then deleted all cookies and 
erased the browsing history, and conducted the same search the region set to the US.

We transferred the URLs from each search result to an MS Excel spread sheet, noting the country and result number. Google Chrome automatically omits similar results, so we collected all of the URLs for each search until we reached the automatically generated message "In order to show you the most relevant results, we have omitted some entries very similar to the [\#] already displayed. If you like, you can repeat the search with the omitted results included." After, visiting and reading each webpage, we excluded 35 URLs because they were irrelevant (i.e. not about immune boosting and/or coronavirus), behind a paywall, or inaccessible (i.e. broken links). The resulting data set consisted of 227 webpages.

\section{Content Analysis}

We analyzed the webpages using a coding framework similar to previous studies conducted by our team. ${ }^{20-24}$ Only the content on the webpage linked to the URL was coded. We first coded the typology of the websites in which the webpages appeared (Table 1). Webpages were then coded for how immune boosting and supplements were portrayed, whether an immune boosting product or service was being sold or advertised on the webpage, and whether the microbiome or gut health was mentioned. For webpages that portrayed immune boosting as beneficial to preventing COVID-19, we recorded the suggested immune boosting strategies. Webpages that suggested taking vitamins and minerals (e.g., Vitamin C, Zinc) through food and/or supplements were coded for those specific vitamins or minerals, not food or supplement. Similarly, we recorded an immune boosting strategy as "supplements and vitamins" when the webpage made a general reference to these types of products or in reference to taking a multivitamin or supplement with multiple immune boosting ingredients.

Table 1: Examples of website typologies used in this study

\begin{tabular}{|ll|}
\hline Typology & Example \\
\hline News & https://www.express.co.uk \\
& https://www.cbc.ca/news \\
Commercial & https://delightyoga.com \\
& https://www.previnex.com \\
Magazine & https://www.yogajournal.com \\
& https://www.womensrunning.com \\
Blog & https://www.romper.com \\
& https://www.sassymamasg.com \\
Health Portal & https://www.medicaldaily.com \\
& https://www.healthing.ca \\
\hline
\end{tabular}




\begin{tabular}{|ll|}
\hline Non-profit organization & https://www.goodgrub.org \\
& https://www.zmescience.com \\
Professionals & https://health.clevelandclinic.org \\
& https://discoveries.childrenshospital.org \\
Scientific journals & https://www.ncbi.nlm.nih.gov \\
& https://www.e-jer.org/journal \\
Government body or governing body & https://www.who.int \\
& http://www.bccdc.ca \\
Other & https://newsthump.com \\
& https://www.sycamorespringssl.com \\
\hline
\end{tabular}

Two coders analyzed the entire data set of URLs. To determine reliability of coding, a third coder coded the subjective items in a sample of 45 URLs, roughly $20 \%$ of the data set. Inter-coder reliability was calculated for these items. Cohen's kappa for typology of the website, portrayal of immune boosting, and portrayal of supplements were calculated at $0.886,0.900,0.962$ respectively, demonstrating appropriate agreement. ${ }^{25} \mathrm{An}$ audit of the immune boosting strategies was conducted by the third coder to determine accuracy. Disagreements were discussed between two coders, CR and AM, until agreement was reached.

\section{Statistical Analysis}

Data were analyzed using descriptive statistics in SPSS 25. We used the Chi-square test to compare website typologies and portrayals, to compare results from the search in Canada and the search in the US, and to compare the whole data set to the top 20 search results generated by each search, since these results have a higher chance of being read. ${ }^{26}$

\section{Ethics Approval}

Ethical approval was not sought because this research did not involve human participants.

\section{Results}

The search in Canada yielded 171 websites and the search in the US yielded 173 websites, with 117 URLs overlapping, 54 URLs being unique to the Canadian search, and 56 being unique to the US search. No significant differences were found in the results between Canada and the US for website typology $\left(X^{2}(9, \mathrm{~N}=344)=5.35, \mathrm{p}=\right.$ $.803)$, portrayal of immune boosting $\left(X^{2}(2, \mathrm{~N}=344)=1.24, \mathrm{p}=.538\right)$, and portrayal of supplements $\left(X^{2}(2, N=344)=0.98, p=.614\right)$. Similarly, no significant differences were found between the whole data set and the webpages that appeared in the top 20 search results for website typology $\left(X^{2}(9, \mathrm{~N}=252)=8.65, \mathrm{p}=.470\right)$, portrayal of 
immune boosting $\left(X^{2}(2, \mathrm{~N}=252)=4.76, \mathrm{p}=.094\right)$, and portrayal of supplements $\left(X^{2}\right.$ $(2, N=252)=0.033, p=.984)$. Since no significant differences were observed between the search results for the two regions, we present the results from analysis of the whole data set of 227 unique URLs. For results associated with the top 20 search hits, we include the webpages that appear in the top 20 search results of at least one of the regional searches, for a total of 25 webpages.

The two primary types of websites were news and commercial websites (Table 2). News sites made up over $50 \%$ of the websites that appeared in the top 20 search results, while commercial sites only made up $16 \%$. In many cases, the typology of websites was difficult to discern, as evidenced by the high number of websites coded as "other", and many sites exhibited characteristic features of more than one typology, for example, a news-style website that was advertising a specific immune boosting supplement. Therefore, we also coded whether the webpage was selling or advertising a specific product or service related to immune boosting. About $20 \%$ of the webpages $(n=48)$ were selling or advertising a specific product.

Table 2. Typology of Websites

\begin{tabular}{|l|r|r|}
\hline Typology & $\begin{array}{l}\text { All websites } \\
(\mathbf{n = 2 2 7 )}\end{array}$ & $\begin{array}{l}\text { Top 20 results } \\
(\mathbf{n = 2 5 )}\end{array}$ \\
\hline News & $92(40.5 \%)$ & $13(52 \%)$ \\
\hline Commercial & $56(24.7 \%)$ & $4(16 \%)$ \\
\hline Other & $20(8.8 \%)$ & $1(4 \%)$ \\
\hline Magazine & $19(8.4 \%)$ & $2(8 \%)$ \\
\hline Blog & $15(6.6 \%)$ & $1(4 \%)$ \\
\hline Health Portal & $12(5.3 \%)$ & $1(4 \%)$ \\
\hline Non-profit organization & $4(1.8 \%)$ & $2(5 \%)$ \\
\hline Professionals & $4(1.8 \%)$ & 0 \\
\hline Scientific Journals & $3(1.3 \%)$ & 0 \\
\hline Government or governing body & $2(0.9 \%)$ & $1(4 \%)$ \\
\hline
\end{tabular}

We coded the webpages for whether the concept of immune boosting was portrayed as neutral, unscientific, or beneficial for preventing COVID-19 (Table 3). Over 85\% of webpages portrayed the concept of immune boosting as beneficial, with less than $10 \%$ of the webpages critiquing the concept of immune boosting. We also coded each webpage for portrayal of supplements as a way to boost immunity (Table 4). Almost half of the webpages did not refer to supplements and were coded as neutral, but $40 \%$ of the webpages portrayed supplements as beneficial to boosting immunity, highlighting that when supplements were mentioned it was largely in a positive fashion. 
Table 3. Portrayal of immune boosting

\begin{tabular}{|l|r|r|}
\hline & All websites & Top 20 results \\
\hline Neutral & $12(5.3 \%)$ & $4(16 \%)$ \\
\hline Unscientific & $21(9.3 \%)$ & $3(12 \%)$ \\
\hline Beneficial & $194(85.5 \%)$ & $18(72 \%)$ \\
\hline
\end{tabular}

Table 4. Portrayal of supplements

\begin{tabular}{|l|r|r|}
\hline & All websites & Top 20 results \\
\hline Neutral & $109(48 \%)$ & $12(48 \%)$ \\
\hline Unscientific & $27(11.9 \%)$ & $3(12 \%)$ \\
\hline Beneficial & $92(40 \%)$ & $10(40 \%)$ \\
\hline
\end{tabular}

We included the microbiome or gut health within our coding framework as it was frequently mentioned in relation to immune boosting. Over $30 \%(n=70)$ of websites mentioned the microbiome or gut health, which was generally intertwined within the narrative of immune boosting, and emphasised its importance for overall health. For example, one webpage states, "Yogurt is considered a probiotic that is essential to your immune system's health. It directly affects your gut, helping the good bacteria to thrive. Your gut health is directly associated with your immune system. Therefore, a healthy gut means a healthy immune system."27

To assess the degree to which different types of webpages represent the concept of immune boosting, we compared website typology with the portrayal of immune boosting and supplements, mention of the microbiome or gut health, and whether the webpage was selling or advertising an immune boosting product or service. Commercial websites were significantly more likely to portray immune boosting ( $X^{2}$ $(2, \mathrm{~N}=227)=7.57, \mathrm{p}=.023)$ and supplements $\left(X^{2}(2, \mathrm{~N}=227)=8.97, \mathrm{p}=.011\right)$ as beneficial and were more likely to be selling or advertising a product $\left(X^{2}(1, \mathrm{~N}=\right.$ $227)=63.64, p=<.0001)$ than the others. There was no significant difference in whether different types of websites mentioned microbiome or gut health $\left(X^{2}(9, \mathrm{~N}=\right.$ 227) $=14.08, p=.119$ ).

We coded 82 different strategies that were suggested as a way to boost immunity. Figure 1 shows the strategies that appeared in more than $10 \%$ of the total dataset of webpages. The most common strategies, Vitamin C $(n=79)$ and diet $(n=79)$, appeared in almost $35 \%$ of the webpages. In contrast, the most common strategies in the top 20 search results are sleep $(n=11)$, diet $(n=10)$, and exercise $(n=9)$, which appeared in $44 \%, 40 \%$, and $36 \%$ of these websites respectively. 
Figure 1. Immune boosting strategies ( $>10 \%$ of websites)

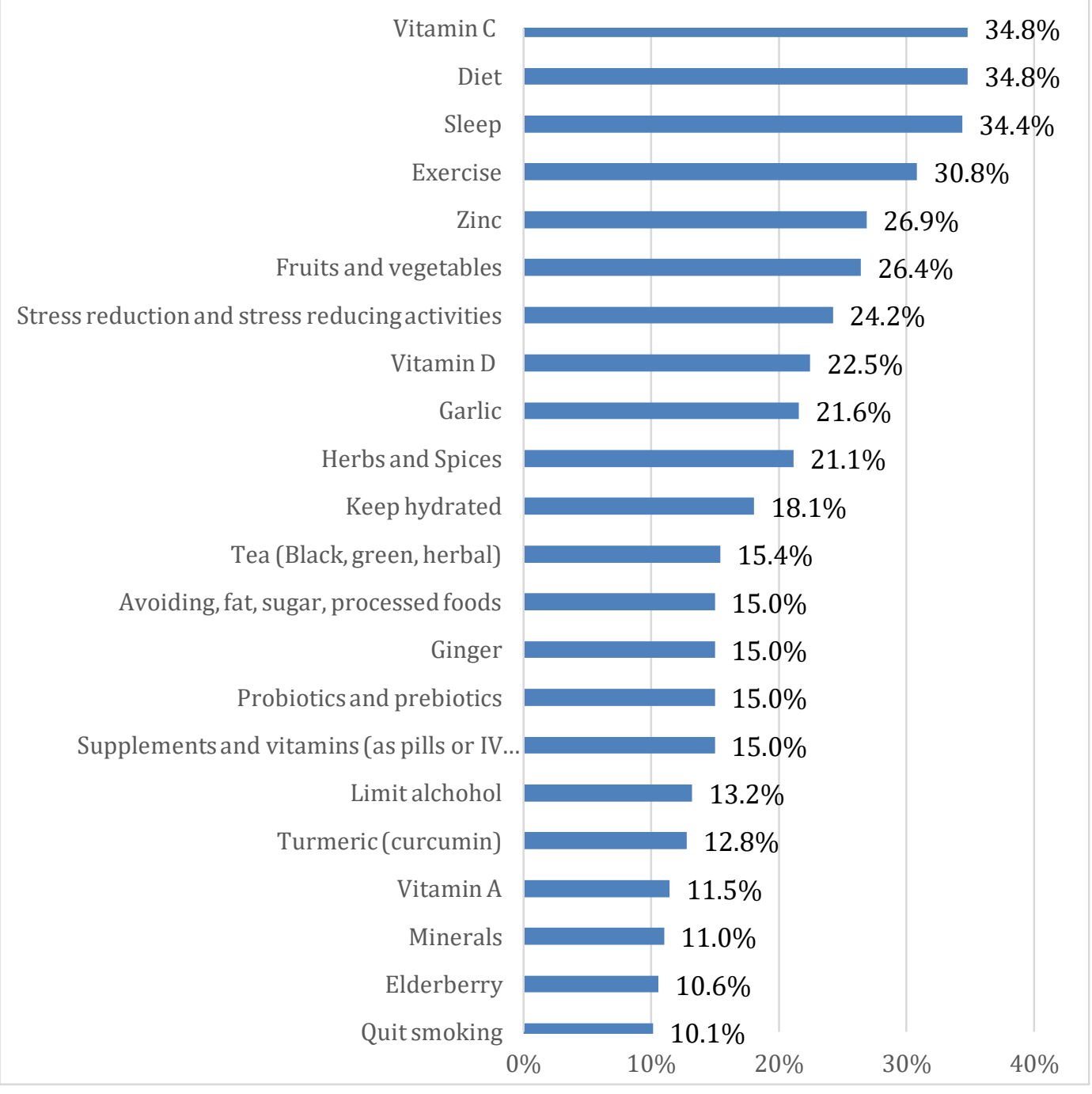

\section{Discussion}

Our study highlights the dominance of the concept of immune boosting during this global pandemic. A large portion of the webpages (85.5\%) portray immune boosting as beneficial, providing no critical scientific content and explicitly or implicitly suggesting the efficacy of boosting the immune system. In comparison to previous studies that find a large presence of commercial websites, ${ }^{18,28}$ less than a quarter of the websites in our dataset (24.7\%) are commercial, and only $20 \%$ of webpages were selling a specific immune boosting product or service. However, $40 \%$ of webpages portrayed supplements, such as vitamins, as beneficial for boosting immunity, which indirectly supports a hugely popular multi-billion dollar industry 29,30 with largely no scientific basis to support the "immune boost" claim. ${ }^{8,9}$ Similarly, while others found that commercial websites were somewhat hidden further down in search results, 18,28 there were only minor variations in the types of websites and how the webpages portrayed immune boosting and supplements 
between the whole data set and the webpages that appeared in the top 20 of search results.

Despite many of the webpages citing supplements as beneficial to boosting the immune system, diet, sleep, exercise, and stress reduction are some of the most common strategies suggested. Eating a balanced diet, getting sufficient sleep, exercising regularly, and reducing one's stress levels are well known to be strategies for maintaining health under any circumstances. However, the explanations from webpages for how these strategies prevent COVID-19 are framed as not just for health, but for boosting immunity. This suggests that the concept of "immune boosting" has taken on a broader meaning and seems to be deployed to attract interest in the products or ideas being put forth. The phrase is now ubiquitous and has likely taken on a "health halo", 31 not unlike other wellness terms that lack clear definition or health benefits, such as "natural", or "gluten-free". ${ }^{32,33}$ The microbiome or gut health were also mentioned as an important part of boosting immunity in $30.8 \%$ of the webpages. This is an example of using the rhetoric around an emerging area of science to legitimize unproven approaches to health - a tactic that has been deployed in other contexts. ${ }^{34,35}$

The reification of the phrase "immune boosting" when paired with solid advice for maintaining one's health (e.g., healthy diet, exercise, sleep) and with language from genuine areas of science, such as microbiome research, may inadvertently help to legitimize the concept, making it a more potent marketing tool. Diet, sleep, and exercise are among the top 5 strategies suggested in commercial webpages and the microbiome is mentioned in $39.3 \%$ of commercial webpages, which means that immune boosting strategies that lack evidence are often described on par, or in association, with sound advice for maintaining health with little to indicate the difference to readers. This framing forms one of the core kinds of misinformation portrayed by the immune boosting narrative. It is often an implied, rather than explicit, form of misinformation - where the context and associations to other health actions or relevant science suggest efficacy and benefit. Perhaps more troubling are the advertisements of products and services intertwined within this immune boosting narrative. Policy responses - including regulatory action - will need to grapple with these less overt forms of health misinformation.

\section{Limitations}

Our sample of webpages is based on a specific query conducted at two points in time in two regions. Variations in search terms or repeated searches at different points in time may have provided different sets of webpages. Additionally, we limited our search and analysis to English-language webpages and our results cannot be generalized to other languages.

\section{Conclusion}

The results from our study demonstrate how the spread of misinformation is complex and often more subtle than blatant fraudulent claims. The public is increasingly going online for health information ${ }^{36}$ and questions persist around the 
kinds of inaccurate information the public is absorbing and the impacts it may be having on health-related decisions and actions. It is unknown, for example, whether large numbers of the North American public have felt that strengthening their immune system has allowed them to participate in less social distancing. Also unclear is whether immune boosting ideas have clashed with the messaging from public health experts. This study demonstrates, however, that in the case of pandemic like COVID 19 conflictive messaging exists online and presents significant challenges for the public seeking scientifically accurate information and advice.

\section{Data Sharing}

The data set is available upon request.

\section{Acknowledgments}

The authors would like to thank Robyn Hyde-Lay for support for this project. The authors would also like to thank the Canadian Institutes for Health Research, Alberta Innovates, the Ministry of Economic Development, Trade and Tourism, the Government of Alberta, the Government of Canada, Genome Canada and Genome Alberta for their generous support of the following projects: 1) Coronavirus Outbreak: Mapping and Countering Misinformation; 2) Critical Thinking in the Digital Age: Countering Coronavirus Misinformation, and; 3) Childhood Asthma and the Microbiome - Precision Health for Life: The CHILD Study.

\section{References}

1. Depoux A, Martin S, Karafillakis E, Bsd RP, Wilder-Smith A, Larson H. The pandemic of social media panic travels faster than the COVID-19 outbreak. J Travel Med. 2020; taaa031. Available from: https://doiorg.uml.idm.oclc.org/10.1093/jtm/taaa031

2. Vaezi A, Javanmard SH. Infodemic and risk communication in the era of CoV-19. Adv Biomed Res. 2020;9:10.

3. Zarocostas J. How to fight an infodemic. Lancet. 2020 Feb 29;395(10225):676.

4. Ferrara E. \#COVID-19 on Twitter: Bots, conspiracies, and social media activism. 2020 Apr 20;arXiv:2004.09531.

5. Liu M, Caputi TL, Dredze M, Kesselheim AS, Ayers JW. Internet searches for unproven COVID-19 therapies in the United States. JAMA Intern Med. 2020; doi:10.1001/jamainternmed.2020.1764

6. Smout A, Sandle P. Misinformation ruins lives, UK fact-checker says. National Post [Internet]. 2020 Apr 30; Entertainment. Available from: https://nationalpost.com/pmn/entertainment-pmn/misinformation-ruinslives-uk-fact-checker-says

7. Iacurci G. Americans have lost $\$ 13.4$ million to fraud linked to Covid-19. CNBC [Internet]. 2020 Apr 15; Finance. Available from: https://www.cnbc.com/2020/04/15/americans-have-lost-13point4-million-tofraud-linked-to-covid-19.html

8. BBC Two. Can I really boost my immune system? [Internet]. London, UK; 2020. Available from: 
https://www.bbc.co.uk/programmes/articles/1bGNzff3qDWhyXKFchKJb6h/ca n-i-really-boost-my-immune-system

9. Harvard Health Publishing. How to boost your immune system. [Internet]. Boston; 2014 September. Available from:

https://www.health.harvard.edu/staying-healthy/how-to-boost-your-immunesystem

10. Shi Y, Wang Y, Shao C, Huang J, Gan J, Huang X, Bucci E, Piacentini M, Ippolito G, Melino G. COVID-19 infection: The perspectives on immune responses. Cell Death Differ. 2020;27:1451-1454.

11. Stump S. Dr. Oz shares 4 ways to strengthen your immune system. Today [Internet]. 2020 Mar 9; Health \& Wellness. Available from: https://www.today.com/health/how-boost-your-immunity-dr-oz-sharesadvice-coronavirus-spreads-t175593

12. Sloan AE, Hutt CA. Repositioning nutraceutical products for growth markets. Nutraceuticals World. 2015;9.

13. Nielsen KE. Health beneficial consumer products - status and trends. In: Osborn S, Morley W, editors. Developing food products for consumers with specific dietary needs. Cambridge, MA: Woodhead Publishing; 2016. pp. 15-42.

14. Bursztyn L, Rao A, Roth C, Yanagizawa-Drott D. Working paper No. 2020-44. Misinformation during a pandemic. Becker Friedman Institute for Economics. 2020 April. Available from: https://bfi.uchicago.edu/wpcontent/uploads/BFI_WP_202044.pdf

15. Blouin-Genest G, Carignan ME, David MD, Généreux M, Roy M. COVID-19: Des troubles de stress et d'anxiété bien présents au Québec et au Canada, aggravés par la désinformation. Université de Sherbrooke. 2020 April. Available from: https://www.usherbrooke.ca/actualites/nouvelles/nouvellesdetails/article/42735/

16. Cohen A. Why Canada's response to COVID-19 is so different from that of the U.S. Ottawa Citizen [Internet]. 2020 March 24; Opinion/Columnists. Available from: https://ottawacitizen.com/opinion/cohen-why-canadas-response-tocovid-19-is-so-different-from-that-of-the-u-s/

17. Yousif N. Canadians have more faith in government than Americans and Brits and less fear for their lives. Macleans [Internet]. 2020 March 26; Health.

Available from: https://www.macleans.ca/society/health/canadians-havemore-faith-in-government-to-handle-coronavirus-than-americans-and-britsand-less-fear-for-their-lives /

18. Macedo AC, Oliveira Vilela de Faria A, Ghezzi P. Boosting the immune system, from science to myth: Analysis the infosphere with Google. Front Med. 2019;6:165.

19. Statista. Worldwide desktop market share of leading search engines from January 2010 to January 2020. 2020 March. Available from: https://www.statista.com/statistics/216573/worldwide-market-share-ofsearch-engines/

20. Rachul C, Caulfield T. Gordie Howe's Stem Cell 'Miracle': A Qualitative Analysis of News Coverage and Readers' Comments in Newspapers and Sports Websites. Stem Cell Rev Rep. 2015 Oct 1;11(5):667-75. 
21. Marcon AR, Murdoch B, Caulfield T. Fake news portrayals of stem cells and stem cell research. Regen Med. 2017 Oct;12(7):765-75.

22. Caulfield T, Marcon AR, Murdoch B. Injecting doubt: responding to the naturopathic anti- vaccination rhetoric. J Law Biosci. 2017 Jun 20;4(2):229-49.

23. Rachul C, Rasko JE, Caulfield T. Implicit hype? Representations of platelet rich plasma in the news media. PloS One. 2017 Aug 9;12(8):e0182496.

24. Marcon AR, Bieber M, Caulfield T. Representing a "revolution": how the popular press has portrayed personalized medicine. Genet Med. 2018 Sep;20(9):950.

25. McHugh ML. Interrater reliability: The kappa statistic. Biochemia medica. 2012;22(3):276-282.

26. Petrescu P. Google organic click-through rates in 2014. Moz. 2014 October 1. Available from: https://moz.com/blog/google-organic-click-through-rates-in2014

27. HealthifyMe. Top 10 Foods to Build your Immune System. 2020 March 25. Available from: https://www.healthifyme.com/blog/top-10-foods-to-boostyour-immune-system/

28. Aslam R, Gibbons D, Ghezzi P. Online information on antioxidants: information quality indicators, commercial interests, and ranking by google. Front Public Health. 2017;5:90. doi: 10.3389/fpubh.2017.00090.

29. Clarke TC, Black LI, Stussman BJ, Barnes PM, Nahin RL. Trends in the use of complementary health approaches among adults: United States, 2002-2012. National health statistics reports. 2015 Feb 10;(79):1.

30. Grand View Research. Dietary supplements market size, share \& trends analysis report by ingredient (vitamins, minerals), by form, by application, by end user, by distribution channel, by region, and segment forecasts, $2020-2027.2020$ February. Available from: https://www.grandviewresearch.com/industryanalysis/dietary-supplements-market

31. Sundar A, Kardes FR. The role of perceived variability and the health halo effect in nutritional inference and consumption. Psychol Mark. 2015 May;32(5):51221.

32. Boyer G, Caulfield T, Green PH, Lebwohl B. Promotion of testing for celiac disease and the gluten-free diet among complementary and alternative medicine practitioners. Am J Gastroenterol. 2019 May 1;114(5):786-91.

33. Iles IA, Pearson JL, Lindblom E, Moran MB. "Tobacco and water": Testing the health halo effect of natural American Spirit cigarette ads and its relationship with perceived absolute harm and use intentions. Health Commun. 2020; Available from: https://doi.org/10.1080/10410236.2020.1712526

34. Caulfield T. Microbiome research needs a gut check. Folio. 2019 October 16. Available from: https://www.folio.ca/commentary--microbiome-researchneeds-a-gut-check/

35. Murdoch B, Zarzeczny A, Caulfield T. Exploiting science? A systematic analysis of complementary and alternative medicine clinic websites' marketing of stem cell therapies. BMJ Open. 2018 Feb 1;8(2):e019414.

36. Shearer E, Gottfried J. News use across social media platforms 2017. Pew Research Center. 2017 Sep 7;7(9):2017. 